\title{
A cortesia negativa na interação discursiva com falantes cultos de Porto Velho-RO
}

DOI: http://dx.doi.org/10.21165/el.v48i3.2321

\author{
Rosa Maria Aparecida Nechi Verceze ${ }^{1}$
}

\section{Resumo}

O artigo procura discutir o fenômeno da cortesia no texto falado de informantes de Porto Velho-RO com o objetivo de analisar a ocorrência dos procedimentos linguísticos da cortesia negativa utilizados para suavizar os atos que ameaçam as faces "FTA" em dois recortes de inquéritos desses informantes. Os FTA correspondem a fórmulas linguísticas e pragmáticas, cujas funções exercidas sobre a face negativa dos interlocutores podem minimizar, salvaguardar ou proteger as faces, favorecendo a cooperação e a negociação em uma situação de interação. A pesquisa se fundamenta na pragmática, no que concerne aos atos de fala (AUSTIN, 1990), no que se refere ao Princípio de Cooperação (GRICE, 1975), na Cortesia (BROWN; LEVINSON, 1987) e na análise dos procedimentos linguísticos da cortesia negativa (KERBRAT-ORECCHIONI, 2006). No que tange à metodologia, a pesquisa tem base etnográfica, consiste num estudo de caso, e se propõe a analisar dois recortes de inquéritos de fala selecionados da pesquisa de pósdoutoramento: "A cortesia na língua culta falada em Porto Velho".

Palavras-chave: língua falada; preservação das faces; cortesia negativa; procedimentos linguísticos; fórmulas linguísticas.

1 Universidade Federal de Rondônia (UNIR), Porto Velho, Rondônia, Brasil; rosa_nechi@hotmail.com; https://orcid.org/0000-0002-6891-7929 


\title{
The negative Courtesy in the discursive interaction with cultured speakers of Porto Velho-RO
}

\begin{abstract}
The article tries to discuss the phenomenon of courtesy in the spoken text from Porto Velho-RO informants with the objective of analyzing the occurrence of negative courtesy linguistic procedures used to soften acts that threaten "FTA" faces in two informant surveys. FTAs correspond to linguistic and pragmatic formulas, whose functions exercised on the negative side of the interlocutors can minimize, safeguard or protect the faces, favoring cooperation and negotiation in a situation of interaction. The research is based on pragmatics, with respect to speech acts (AUSTIN, 1990), regarding the Principle of Cooperation (GRICE, 1975), Courtesy (BROWN and LEVINSON, 1987) and analysis of linguistic procedures of the negative courtesy (KERBRAT-ORECCHIONI, 2006). Regarding the methodology, the research has an ethnographic basis. It consists of a case study, and it proposes to analyze two cuts of speech surveys selected from the postdoctoral research: "A Cortesia na Língua Culta Falada em Porto Velho".
\end{abstract}

Keywords: spoken language; face preservation; negative courtesy; language procedures; language formulas.

\section{Introdução}

O indivíduo se diz cortês ao conviver com seus parceiros de comunicação com delicadeza, amabilidade, civilidade, elogiando-os, agradecendo-lhes. Por essas mesmas características no grupo social, as pessoas são corteses. Desta forma, cortesia e polidez são sinônimos, embora na etimologia recebam tratamentos teóricos distintos (HILGERT, 2008). Para este estudo, adotaremos o termo "cortesia", somente mantendo o termo "polidez" em citações diretas.

O estudo da cortesia foi desenvolvido por Robin Lakoff (1973), considerado um dos primeiros autores a falar deste assunto, e nos traz a existência de dois importantes princípios de competência pragmática: ser claro e ser polido. Lakoff (1973) enfatiza que: "A polidez se sobrepõe: é considerado mais importante evitar conflito do que alcançar clareza". Com isso, se deve avaliar que nas relações sociais, mais do que a informação, o que importa é o esforço e autoafırmação para se relacionar nas interações (LAKOFF, 1973). Sendo assim, o segundo princípio de competência pragmática "ser polido", descrito por Lakoff (1973) se desdobra em outras (sub)normas de cortesia: (a) não se imponha; (b) dê opções; (c) faça com que o interlocutor se sinta bem, seja amigável, que se tornam apropriadas no uso da comunicação e contribuem para a produção da cortesia, já que a cortesia ocupa um lugar privilegiado na interação. 
A cortesia como atividade social se torna um fenômeno de aproximação e abordagem entre os interlocutores em busca de um equilíbrio social, no qual se insere a busca da preservação da imagem entre os interlocutores que, na interação, terão direitos e obrigações a desempenhar, alcançando custos e benefícios ou sofrendo danos.

Assim, o objetivo deste artigo consiste em analisar a ocorrência dos procedimentos linguísticos da cortesia negativa utilizados para suavizar os atos que ameaçam as faces "FTA" em dois recortes de inquéritos de falantes cultos de Porto Velho- RO.

A proposta metodológica faz parte da pesquisa de pós-doutorado da pesquisadora: "A cortesia na língua culta falada em Porto Velho", desenvolvida na Faculdade de Filosofia, Letras e Ciências Humanas - FFLCH, terminada em agosto de 2018. Constitui-se da análise de 8 (oito) inquéritos de fala, discutidos em 13 recortes de textos. 0 objetivo consistiu em verificar se os procedimentos linguísticos da cortesia negativa, inseridos ou presentes nos enunciados dos falantes de Porto Velho-RO, produziram a cortesia negativa. Esses inquéritos constituem parte do projeto de pesquisa "Documentação e descrição de português culto falado em Porto Velho: análise da conversação e processos interacionais", que foi finalizado pela pesquisadora em Porto Velho, junto à Universidade Federal de Rondônia. O objetivo do projeto consistiu em "Documentar e descrever o português culto falado em Rondônia". Destaque-se que o projeto possui 52 transcrições selecionadas para compor um banco de dados que está sendo construído e será brevemente disponibilizado on-line.

\section{Contextualização da Pragmática}

Para Fiorin (2012), a pragmática consiste na ciência do uso linguístico que estuda as condições que dirigem a prática linguística. Assegura que a enunciação forma um dos domínios de fatos linguísticos determinantes para a introdução da dimensão pragmática nos estudos linguísticos, posto que a pragmática se constitui no ato de produzir enunciados para a realização linguística concreta.

Nesse sentido, um falante, ao se utilizar da língua para produzir enunciados, usa traços e marcas, ou seja, elementos que remetem à instância de enunciação. Esses conjuntos de marcas enunciativas alocados no interior do enunciado não consistem na enunciação propriamente dita, mas na enunciação enunciada. Sendo assim, o texto possui a enunciação expressa, que incide num conjunto de marcas identificáveis, remetendo à instância de enunciação, e o enunciado se apresenta na sequência pronunciada (dita) desprovida de marcas de enunciação.

Com foco no uso da linguagem, a pragmática se insere na corrente teórico-metodológica que se caracteriza como interlinguística e intercultural, com isso fornecendo um quadro teórico apropriado para o estudo da cortesia, dado que esta como fenômeno social se 
realiza, principalmente, por meio da língua e está relacionada à identidade e conduta dos participantes de uma interação verbal. Conforme destaca Kerbrat-Orecchioni (2006, p. 80), a cortesia consiste num fato que "aparece como um meio de conciliar o mútuo desejo de preservação das faces, com o fato de que a maioria dos atos de fala são potencialmente ameaçados para uma dessas faces".

\subsection{Teoria dos atos de fala: Austin (1990)}

Para o estudo do fenômeno da cortesia, os atos de fala constituem o ponto de partida. A noção de atos de fala surge com o trabalho do filósofo da linguagem J. L. Austin (1962) a partir da obra How to do things whith words ${ }^{2}$ publicada postumamente, em 1962, trazendo à tona a linguagem com a função de agir, de realizar atos por meio da fala.

Nesse trabalho, Austin (1962) destaca que, para a realização de atos de fala ser bemsucedida, há condições diversas. Dessa forma, a teoria dos atos de fala ${ }^{3}$ parte do princípio de que é possível classificar, de forma sistemática, as intenções comunicativas dos falantes e as formas de codificar linguisticamente em contexto, levando em consideração o significado da palavra em seu uso. A ideia básica dos atos de fala apresentada nos estudos de Austin e Searle constitui a linguagem como ação, visto que as expressões linguísticas são capazes de realizar certos tipos de atos comunicativos, como "fazer declarações", "perguntar", "pedir", "prometer", "dar instruções", "desculpar-se", etc.

Sendo assim, para a verificação dos atos de fala, não se parte da análise de sentenças, mas de enunciados, pois compõem atos realizados em situações reais de comunicação. Assim, os atos de fala são vistos como as unidades básicas da comunicação humana.

\subsection{Princípio de Cooperação: Grice (1982)}

Bravo (1999), ao considerar os princípios que provêm da pragmática ortodoxa, ressalta que Grice (1975) elaborou um modelo teórico ortodoxo, posto que, no micro nível do enunciado linguístico, infere a intenção racional, voluntária e consciente dos falantes, a qual se constitui como a unidade de análise do ato de fala para que a mensagem seja interpretada. Nesta interpretação surgem as crenças e valores sociais dos falantes

2 Obra traduzida para o Português como o título: Quando dizer é fazer (1990).

3 Searle, filósofo e discípulo de Austin, ampliou a teoria dos atos de fala desenvolvida por Austin ao propor que a realização do ato de fala é governada por regras. Searle postula que "a realização de um ato de fala envolve a efetivação de vários atos ao mesmo tempo. Dessa forma, decompõe a noção de ato locucionário de Austin, desdobrando-o em ato de enunciação - a emissão de palavras - e ato proposicional - o ato de referir e predicar" (SEARLE, 1981, p. 34-35, grifo do autor). Com efeito, a teoria clássica dos atos de fala se encontra no livro de Searle Speech Acts: An Essay on the Philosophy of Language (SEARLE, (1969[1975] [1976]). 
necessários para que se constituam enquanto agentes racionais dos conhecimentos do "princípio de cooperação" para que a conversação tenha êxito na interação.

Nessa perspectiva, a teoria do princípio de cooperação 4 de Grice (1975) contribui para o estudo da cortesia, posto que, numa conversação, a sequência de enunciados e o conhecimento das regras e dos papéis sociais entre os interlocutores são intercambiáveis, possibilitando aos interlocutores interação e cooperação mútua para que a fala tenha êxito.

Para Grice (1982), há uma distinção entre o que é dito e o que está implícito, respectivamente o significado semântico do enunciado e o significado do contexto da conversação alcançado pelo interlocutor por meio de um raciocínio lógico e dedutivo. Esses dois significados se relacionam ao desenvolvimento da teoria das implicaturas, configurando um sistema de categorias: as máximas conversacionais. ${ }^{5}$

Diante disso, sabe-se que, no processo comunicativo das línguas naturais, as categorias de máximas conversacionais não são adotadas no limite. Ocorrem constantemente as aparentes violações das máximas que geram as implicaturas. Essas são efetivadas com a finalidade de causar um efeito na comunicação, ocasionando a quebra dessas máximas, quando, por exemplo, o interlocutor quer comunicar uma informação e nela deixa parte implícita ou subentendida, que só se recupera numa situação partilhada por inferência, porque há conhecimento de mundo partilhado entre os interlocutores.

\subsection{Construção da Face e da Interação: Goffman (1967)}

Nos estudos de Goffman (1967, 2006, 2011), a interação se relaciona aos enquadres que permitem a formação de quadros de sentidos que harmonizam ou modelam as interpretações dos interlocutores, ao mesmo tempo que assinalam o envolvimento e o posicionamento dos falantes na interação.

Dessa forma, a ordem da interação pode ser compreendida como um contrato social e um consenso social, em que os indivíduos se adaptam a acordos interacionais correntes,

40 artigo The logic of conversation (1982 [1975]) apresenta o Princípio de Cooperação (PCO): "Faça sua contribuição conversacional tal como é requerida, no momento em que ocorre, pelo propósito ou direção do intercâmbio conversacional em que você está engajado" (GRICE, 1982, p. 86).

5 Máxima da Quantidade: Fale somente o necessário. a) Faça sua contribuição tão informativa quanto é requerido pelo propósito do intercâmbio verbal; b) Não faça sua contribuição mais informativa do que é requerido. Máxima da Qualidade: Seja sincero. a) Não diga nada que você acredite ser falso; b) Não diga nada de cuja verdade você não tem prova suficiente. Máxima da Relação (Relevância): Seja relevante. - Máxima de Modo: Seja claro. a) Evite obscuridade da expressão; b) Evite ambiguidade; c) Seja breve; d) Seja ordenado (GRICE, 1982, p. 86-87). 
por uma grande diversidade de razões, que não se pode deduzir de um apoio tácito aparente, visto que irão se opor à mudança.

Por exemplo, numa situação de interação, uma pessoa pode ficar aborrecida e em desacordo, mas se mostrar com ações de conformidade e consenso durante a interação. Com efeito, se escondem combinações de motivos e jogos. Também situações em que indivíduos violam sistematicamente as normas da interação, quase todo tempo, no entanto, são obrigados a aceitá-las. São estes fatos que tornam as pessoas vítimas e culpadas quando infringem as regras sociais, provocando ${ }^{6}$ tumulto. 0 indivíduo evidencia que muitas coisas ficam encobertas ou sem solução para evitar conflitos e manter a ordem no grupo. Isso acontece por medo do confronto direto ou indireto, que pode ocorrer na interação conversacional - criar uma cena indesejável e gerar um desconforto maior no meio social.

Nesse viés, a linha determina a conduta pela qual os interlocutores marcam uma posição enquanto falantes, por isso, a linha leva as pessoas a se posicionar na "face", definida como "um valor social positivo que uma pessoa efetivamente reivindica para si mesma através da linha que os outros pressupõem que ela assumiu durante um contato particular" (GOFFMAN, 2011, p. 13-14). A face se torna a imagem que se tenciona mostrar de si e que é aderida, a partir das atitudes institucionalizadas socialmente. Neste sentido, a face se torna sustentada pelo valor social positivo e também por um padrão de comportamento que o interlocutor decide mostrar e manter em suas interações face a face.

Portanto, a face é um construto social constituindo apenas um empréstimo que foi dado pela sociedade aos participantes e essa lhes pode ser retirada, caso os comportamentos não sejam merecedores.

\subsection{Estudo da Cortesia}

Para Silva (2008, p. 163), a cortesia consiste num "ato de manifestar atenção, respeito ou afeto que uma pessoa tem por outra ou, ainda, um conjunto de regras mantidas no trato social com o outro para demonstrar consideração".

Com efeito, a cortesia linguística busca examinar discursos verbais e não-verbais que expressem atos corteses e descorteses realizados pelos falantes nas diferentes práticas de comunicação social. A sociedade determina um conjunto de normas que impõe aos

6 Goffman (1967) desenvolve estudos relacionados à investigação da imagem do indivíduo em situação de interação com a obra Interaction ritual: essays in face to face behavior (1967) pela qual desenvolve o conceito de "linha" compreendendo um padrão de atos verbais e não verbais de um indivíduo que expressa a sua visão da situação, a sua avaliação dos participantes, e sobretudo, a de si mesmo durante uma situação de interação social. 
falantes, visando controlar o comportamento dos seus membros. As considerações de Alvarez Muro (2014) ressaltam que a sociedade humana não pode existir sem o respeito pelas regras sociais; a sociedade só se torna harmoniosa quando os seus membros obedecem às normas e se comportam de acordo com os valores sociais regidos. Espera-se que cada membro social tenha o respeito mútuo pelos parceiros sociais; haja o respeito específico e uma "valiosa cópia homo sapiens" (ALVAREZ MURO, 2014, p. 37). Isso é precisamente o início e o fim da cortesia.

Haverkate (1994, p. 14) enfatiza que, nas interações verbais com diálogo ou mesmo sem diálogo, a cortesia linguística possui um substrato: "conceito que está intimamente ligado ao de boa educação e de delicadeza, tal como o próprio conceito de conduta verbal, remetendo para o cariz sociolinguístico dos mecanismos de cortesia linguística, que faz referência a uma espécie de contrato social-conversacional".

Para a construção da cortesia na conversa, é necessária a boa educação, a delicadeza e bom comportamento entre os interlocutores para a preservação das faces e da cortesia negativa, o que ocasiona o equilíbrio e sucesso da conversa. Na sociolinguística, no uso das modalidades de variações da língua, a cortesia também tem seu efeito. Em cada variedade linguística, os interlocutores negociam os procedimentos linguísticos da cortesia para a eficácia da comunicação.

A cortesia está inserida nas normas sociais de toda língua em qualquer sociedade, a qual regula o comportamento adequado de seus membros, o ajuste a uma norma ou modalidade pela qual torna o diálogo cortês. Dessa maneira, a cortesia, como produto da necessidade humana é imprescindivel para manter o equilíbrio nas relações interpessoais. Sua manifestação é produzida por um conjunto de estratégias linguísticas que são utilizadas por falantes para atenuar o conflito na interação quando os interesses dos interlocutores não se ajustam (ESCANDELL-VIDAL, 1995).

\section{Teoria da Cortesia Linguística: Brown e Levinson (1987)}

Com base em um vasto estudo que incluiu observações e análises de línguas ${ }^{7}$, Brown e Levinson (1987) elaboraram a teoria da cortesia e passaram a presumir que a universalidade da cortesia está presente nas trocas de turnos conversacionais como um fator regulador da fala. Consideraram, então, o trabalho de Grice a respeito das máximas conversacionais e observaram que, durante a interação, os falantes cometem desvios delas, ou seja, a maioria dos atos de fala produzidos na interação não ocorre de forma tão eficiente como sugeria Grice. Com efeito, Brown e Levinson (1987) observaram,

7 Brown e Levinson (1987) utilizaram estratégias linguísticas analisadas na fala de três línguas diferentes: o tamil (falado no sul da Índia); o inglês e o tzeltal (língua maia, falada em Tenejapa no México e em outras línguas. 
também, a teoria de Goffman e voltaram sua atenção para os dois desejos básicos do ser humano: o de ser apreciado pelo ouvinte e o de não ter suas ações impedidas por ele. Teoricamente, seria possível produzir uma nova máxima para explicar cada pequena regularidade apreendida no uso da língua. Nessa perspectiva, a cortesia explicaria o desvio da eficácia racional nas interações, sendo comunicada precisamente por meio desse desvio (BROWN; LEVINSON, 1987). Segundo os autores, a cortesia explicaria o desvio da eficiência racional das regras na interação porque seria comunicada através do desvio.

Por esse prisma, Brown e Levinson (1987) construíram um estudo sistemático da língua e da comunicação como uma atividade racional, baseando sua teoria em uma Pessoa Modelo (Model Person - MP), a qual fala uma língua natural fluentemente e possui duas propriedades importantes: racionalidade e face. Então, os autores, a partir do modelo concebem a cortesia linguística como um fenômeno centrado no conceito metafórico de face de Goffman (1967).

Nesse ponto de vista, de certa forma, Brown e Levinson (1987) completam o Princípio de Cooperação de Grice ao abordar os aspectos sociais da comunicação por meio das estratégias de cortesia e, também, expandem o modelo da imagem social elaborado por Goffman, posto que constroem relações entre certas necessidades de imagem e na realização de atos de fala específicos.

Todas as pessoas modelo (model person) têm a face positiva e a face negativa; todas são agentes racionais, ou seja, escolhem meios que satisfaçam suas necessidades interacionais, dado que a face consiste em um conjunto de desejos satisfatórios apenas pelas ações (incluindo expressões de desejos) de outros, em geral, será para o "interesse mútuo de duas pessoas modelos que manterão a face do outro" (BROWN; LEVINSON, 1987, p. 59-60).

A partir da teoria de Goffman, Brown e Levinson (1987) desenvolveram dois conceitos básicos para noção de face: a face positiva refere-se "[...] ao desejo de aprovação social; refere-se à necessidade que todo indivíduo tem de ser aceito, de ser tratado como membro de um grupo" e a face negativa que se refere à [...] "necessidade que todo o indivíduo tem de ser independente, de ter liberdade de ação e de não sofrer imposição" (SILVA, 2008, p. 179).

Sendo a conversação uma atividade com grande potencial para ameaças, a face dos participantes, a cortesia linguística com a noção dos conceitos de face positiva e negativa constitui uma forma de manter o equilíbrio na conversação. Assim, em decorrência de ser a face vulnerável, os atos de fala devem ser atenuados para preservar a face positiva ou a face negativa, tanto do falante quanto do interlocutor durante as interações sociais. 
Nessa perspectiva, o modelo de Brown e Levinson (1987) tem os estudos voltados para a análise dos Atos Ameaçadores de Face (AAF), que consiste em atos que podem colocar em ameaça tanto a face positiva, como a face negativa dos interlocutores.

Os AAFs podem ser realizados pelo falante em registro diretamente (on record); ou podem ser realizados fora do registro indiretamente (off record).

No caso das produções de fala realizadas fora de registro, são identificadas pelo fato de não possuírem apenas uma intenção comunicativa, podendo consistir em ironia, metáfora, insinuações, alusões, ambiguidades, entre outros. As produções em registro podem ser construídas em duas formas: uma diretamente, que implica circunstâncias específicas e não compromete a interação (cf. BROWN; LEVINSON, 1987, p. 69). A outra se manifesta com a utilização de um AAF (ato de ameaça à face) com ação compensatória e compreende o uso de estratégias de cortesia positiva e de cortesia negativa.

Dessa forma, para Brown e Levinson (1987), a cortesia passa, essencialmente, pela decisão do falante de realizar um FTA sem invadir os desejos de imagem (face want) do interlocutor e/ou sem perder a própria face, dado que, conforme Kerbrat-Orecchioni (2006, p. 80), "a perda da face é uma falha simbólica que tentamos evitar, na medida do possível, a nós mesmos e aos outros".

\subsection{Estratégias da Cortesia para Brown e Levinson (1987)}

Para Brown e Levinson, (1987, p. 102), as estratégias positivas têm o objetivo de possibilitar "a aproximação e a solidariedade" entre os participantes, ao mesmo tempo, consistindo numa estratégia que procura preservar a face positiva do ouvinte, constituindo um complemento para a tentativa de ameaça da face. Os autores elencaram as seguintes estratégias de cortesia positiva (cf. BROWN; LEVINSON, 1987): i) veicular que o interlocutor é admirável, interessante; ii) reivindicar marcas de identidade do grupo; iii) reivindicar aspectos em comum, como pontos de vista, opiniões, atitudes, conhecimentos, empatia; iv) veicular que locutor e interlocutor são cooperativos; v) satisfazer o desejo do interlocutor (BROWN; LEVINSON, 1987).

Quanto às estratégias negativas, têm o objetivo de enfatizar "a distância" (BROWN; LEVINSON, 1987) entre locutor e interlocutor, consistindo em uma estratégia que visa a preservar a face negativa do ouvinte por meio de diferentes estratégias linguísticas de atenuação; atua no sentido de tentar evitar a imposição ao ouvinte. Fornece um comportamento de respeito por parte do falante e fundamenta-se em tópicos que o falante deve evitar como: a invasão do território pessoal do ouvinte para não interferir na liberdade de ação dele. Os autores relacionam as seguintes estratégias: i) não ser direto; ii) não presumir ou assumir, utilizar perguntas e rodeios; iii) não forçar o interlocutor e dar a opção de não fazer o que se pede; iv) não fazer imposição ao interlocutor ao comunicar 
os desejos, dissociando-o da violação; v) reparar outros desejos, derivados da face negativa; vi) minimizar a imposição; questionar, atenuar (futuro do pretérito: "poderia"); vii) pedir desculpas; viii) impessoalizar o falante e o ouvinte (BROWN; LEVINSON, 1987).

\section{Contribuições de Catherine Kerbrat-Orecchioni para o Estudo da Face e dos Procedimentos Linguísticos}

De acordo com Kerbrat-Orecchioni (2006, p. 87), a cortesia "aparece como um meio de conciliar o desejo mútuo de preservação das faces com o fato de que a maior parte dos atos de linguagem produzidos, ao longo da interação, são potencialmente ameaçadores para uma ou outra dessas mesmas faces". Toda interação com dois ou mais participantes, os atos verbais ou não-verbais realizados, está submetida na sua totalidade ou quase totalidade a ameaças potenciais para uma ou outra face. Diante disso, a autora reconhece as contradições nos efeitos de cortesia no Modelo de Brown e Levinson (1987) e, assim, introduz um novo conceito para completar os estudos dos autores, assinalando algumas limitações na teoria por eles proposta.

No entanto, Kerbrat-Orecchioni também reconhece que essas limitações não anulam o poder teórico descritivo do modelo, uma vez que pode ser expandido e aprimorado. A teoria de Brown e Levinson focaliza apenas os atos potencialmente ameaçadores para as faces que incide em atos em que as pessoas estão permanentemente sob a ameaça de FTAs nas interações. Por isso, Kerbrat-Orecchioni (2006) desenvolve o estudo dos atos valorizantes para as faces, como os elogios, os agradecimentos ou os votos. Com isso, em oposição à noção de FTA, apresenta a noção de FFAs (face-flattering acts), atos que valorizam a face, constituindo-se em "anti-FTAs". Nesse sentido, os atos de fala se distribuem em dois grupos: aqueles que produzem efeitos essencialmente negativos para as faces, como ordens ou críticas; e aqueles essencialmente positivos, como elogios e agradecimentos (op. cit., 2006, p. 82).

Desse modo, com a introdução da noção de FFAs, a linguista francesa estabelece uma modificação relevante no esquema das estratégias da cortesia desenvolvidas por Brown e Levinson. Ao considerar a reelaboração realizada para os dois tipos de cortesia, KerbratOrecchioni (2006) ressalta que a cortesia negativa é de cunho compensatório e reparador e consiste em evitar a realização de FTA ou em minimizar a produção de um FTA por meio de algum procedimento (ordem indireta - asserção, moderadores, desarmadores, impessoalização, etc.) indiferente de tal ato direcionar-se à face positiva ou negativa dos interlocutores. A cortesia positiva, por sua vez, consiste em atos de valorização da face dos interlocutores, sendo a face positiva ou negativa. Exemplos: quando utilizamos formas de elogios, agradecimentos. 


\subsection{Procedimentos Linguísticos da Cortesia}

A partir da modificação para os dois tipos de cortesia, Kerbrat-Orecchioni (2006) estabelece os procedimentos linguísticos para cortesia negativa e positiva. Para a cortesia negativa proporciona uma relação dos procedimentos linguísticos, dividindo-os em substitutivos e subsidiários. Para a cortesia positiva, apresenta um esquema de fórmulas de apreciação positiva e negativa.

Os procedimentos substitutivos são acompanhantes verbais de cortesia negativa que os interlocutores utilizam para atenuar a ameaça potencial de um ato de fala. Ocorre quando uma formulação explícita de um FTA é substituída por outra mais atenuada e abrangem: (1) a indiretividade - realização de ordem por meio de pergunta ou asserção; (2) os desatualizadores, modais e temporais - utilização ou combinação de modalidades: condicional, pretérito imperfeito, voz passiva (apagamento da referência direta ao(s) interlocutor(es), indeterminação, impessoalização ou o indefinido), pronomes pessoais ("senhor/a" por "você"; "nós" / "a gente", invés de "eu" ou "nós"), solidariedade ou modéstia (KERBRAT-ORECCHIONI, 2006).

Kerbrat-Orecchioni também fornece os procedimentos suavizadores acompanhantes para minimizar a formulação de um FTA: (1) fórmulas de cortesia especializadas, como "por favor" ou "por gentiliza", lexicalizadas e convencionalizadas nas línguas; (2) enunciado preliminar como em "Você tem um minutinho?", antecedendo um pedido ou uma justificativa: as interpelações, as perguntas, as críticas, os convites; (3) minimizadores: parecem reduzir a ameaça do FTA preferidos por falantes no uso de diminutivos; (4) modalizadores como "eu acho", "talvez", "possivelmente", "provavelmente", "me parece que" etc., projetam uma certa distância entre o sujeito da enunciação e o conteúdo do enunciado, fornecendo aspectos mais polidos; (5) desarmadores, pelos quais o falante antecipa uma possível reação negativa do interlocutor e tenta neutralizá-la; (6) moderadores que consistem num tipo de "suavizante", ajudando a "engolir a pílula do FTA" (KERBRAT-ORECCHIONI, 2006).

\section{Análise dos Procedimentos Linguísticos Substitutivos e Subsidiários em dois Recortes de Inquéritos de Falantes de Porto Velho - RO}

Para este artigo, faremos a discussão com um recorte de inquérito, com a utilização de procedimentos linguísticos substitutivos e um com a utilização de procedimentos linguísticos subsidiários. Procuraremos verificar na análise como os interlocutores negociam o diálogo, a preservação da face negativa e, também, como estabelecem a cortesia negativa, por meio desses procedimentos. 


\subsection{Procedimentos substitutivos: atenuar a ameaça potencial de um ato de fala}

Para abordar uma situação de diálogo que apresente o sujeito indeterminado enquanto um recurso autoprotetor do falante, elencamos para análise o recorte 5, a seguir:

\section{Recorte 5}

L1 Tão vendendo até ralo de banheiro... escova de aço ... até lixa chegou agora estes tempos ... lixa de parede

L2 como é o nome daquele negócio ali ... di passar massa? (Inquérito 31 PCFPVHRO)

O Locutor 1 inicia o turno com o verbo "vender" em que o sujeito gramatical de seu enunciado é indeterminado: "tão vendendo". Em seguida, introduz um operador discursivo "até" que produz um efeito de ênfase na sua fala, trata-se de um reforço argumentativo que, devido à força ilocutória, fornece destaque à venda dos produtos e atrai a atenção do interlocutor L2. No entanto, verificamos, pela fala do Locutor 1, um distanciamento do que é dito pelo sujeito enunciador. Assim, a ocultação do "eu" da enunciação, com a construção do sujeito indeterminado, caracteriza a diminuição da responsabilidade de L1 com o que é dito.

Esse tipo de construção linguística, segundo Briz Gómez (2012), atenua e debilita a força argumentativa do falante com relação à verdade do enunciado, o grau de conhecimento e o compromisso do que se fala. Na verdade, se analisarmos o conteúdo enunciado na fala de L1, por exemplo: "ralo de banheiro... escova de aço ... até lixa chegou agora estes tempos ... lixa de parede" não se sabe, exatamente, o que há na loja, por isso a generalização, nem sequer há certeza sobre a existência da loja. Também não há intenção desse reconhecimento, o que importa é a interação.

O grau de compromisso e conhecimento do falante, bem como a expressão de dúvida, possibilidade ou incerteza, acontece através das estratégias que diminuem responsabilidades, "que previnem ou que reparam, são escudos autoprotetores quando não, também protetores do outro. São recursos relativizadores" (BRIZ GÓMEZ, 2012, p. 9).

Nesses parâmetros de análises, nomeadamente, a ocultação do "eu" ou impessoalização do sujeito semântico (o agente) determina procedimentos de atenuação mais recorrentes como: o falante responsável pelo dito se oculta em outro, em um interlocutor genérico que assume o lugar da opinião da maioria. Desta forma, desfocaliza-se na base da enunciação e a enunciação pessoal é enfraquecida (ALBELDA et al., 2014). 
Nesse exemplo, a impessoalização do sujeito L1 atenua a ameaça potencial do ato de fala, estabelecendo a construção da cortesia negativa.

\subsection{Procedimentos Subsidiários: minimizar a formulação de um FTA}

Em seguida, analisamos uma situação de diálogo, o recorte fragmentado dividido em 10 (A) e 10 (B) para mostrar o Minimizador: função de diminuir a ameaça do FTA.

\section{Recorte 10 (A)}

L2- não que nem eu falei pra ela... dona Rose eu sou atendente... mais nem toda hora a gente tá com aquela disposição toda... ocupada pra dar atenção pro cliente... nê? eu dou um boa tarde... converso com o cliente... tudo aí eu peço pra ele aguardar um pouquinho... aí ela tava falando pra mim só do fato de dar uma atenção pro cliente... já é alguma coisa... então eu falei... então tá bom então...

L1 tão usando mais esses cabos

L2 tão usando mais é fio.... (Inquérito 31, PCFPVHRO)

Nesse recorte 10A, Dra. Rose é proprietária, o Locutor 1 e o Locutor 2 são funcionários da loja de materiais de construção. A locutora 2 dirige seu turno à locutora 1 e, durante o desenvolvimento do assunto na fala de L2, fica evidente que ela está falando de uma terceira pessoa do discurso - um cliente. L2 relata sobre o tratamento que fornece aos clientes: "dou uma boa tarde", "converso com o cliente", "tudo aí eu peço pra ele aguardar um pouquinho...". O uso de um minimizador com um sufixo em -inho, como em "pouquinho" no último enunciado, suavizaria o ato ameaçador da face negativa do cliente, caso ele estivesse presente na loja. Esse diminutivo se trata de um minimizador cuja função é parecer minimizar a ameaça que o FTA constitui.

Por outro lado, no início da fala de L2: "... mais nem toda hora a gente tá com aquela disposição toda... ocupada pra dar atenção pro cliente", observamos a falta de compromisso na função de vendedora de $L 2$, posto que com esse enunciado ela procura defender suas faces, confirmando um ato de reparação de face que constitui "escudos autoprotetores" (BRIZ GÓMEZ, 2012, p. 289), conservando a sua face negativa. 


\section{Recorte 10 (B)}

(Entra um cliente na loja, perguntando por gerador)

L2 o gerador... éh di vez em quando vem gente fazer orçamento di gerador mais... isso aí é com seu Vilmar e eu entendo disso aí não

L1 o gerador acho que só com ele mesmo... nem eu entendo ... eu sei que tá anunciado no jornal... nê? Tá na promoção tudo... esse geradores ((toca o celular)) um minutinho

\section{L2 celular tá tocando}

((atendendo o celular)) (Inquérito 31, PCFPVHRO)

Nesse outro fragmento do inquérito 10B, observamos que o Locutor 2 está falando com uma terceira pessoa, ausente da interação, trata-se de um cliente que entra na loja. Ele pergunta por "gerador" e L2 responde com o turno: "éh di vez em quando vem gente fazer orçamento di gerador mais ... isso aí é com seu Vilmar e eu entendo disso aí não". A fala de L2 exibe a ausência de responsabilidade com a verdade das informações que acarreta o enfraquecimento da força argumentativa com relação à certeza do enunciado e também expõe a falta de compromisso do falante com o conteúdo do enunciado (BRIZ GÓMEZ, 2012). Apresenta uma situação em que o falante L2 tenta se "esquivar" do enunciado do compromisso com a verdade da preposição. A falta de compromisso ${ }^{8}$ enunciativo é confirmada quando L2 diz: "e eu entendo disso aí não" negando de modo direto as táticas de incerteza, dúvida e responsabilidade com o enunciado.

Esse tipo de construção, segundo Briz Gómez (2012), atenua e enfraquece a força argumentativa do falante com relação à verdade do enunciado, conhecimento da informação e seu compromisso com a enunciação. De fato, L2 quer "desconversar", encerrar a fala e "despachar" o cliente que está atendendo. L2 compromete sua face negativa.

8 Para Briz Gómez (2003), ao falar de identidade, é preciso considerar a densidade de laços que mantêm o interlocutor com seu próprio grupo e com o outro e seu desejo de se identificar com as pessoas, na medida em que elas participam da ideologia do grupo, ao qual desejam filiar-se. Assim, a identidade do informante interfere na negociação do diálogo na interação, o que permite perceber uma relação social específica, apontando para uma cultura inconsciente, precária e enraizada que subjaz, fruto da experiência sociocultural de indivíduos advindos de uma comunidade linguística que ainda conserva na língua falada "murmúrios europeus" e também de um grande fluxo migratório proveniente de toda região do Brasil, sobretudo, Nordeste e Sudeste. Essa movimentação de migrantes influenciou o contato com falares de diversos extratos regionais que interferem nos processos tanto estruturais quanto de articulação da linguagem, promovendo o surgimento de uma modalidade de fala diferenciada das demais regiões do Brasil. 
Em relação à fala do Locutor 1 , averiguamos a sua colaboração com a fala de L2: "O gerador acho que só com ele mesmo... nem eu entendo", assumindo também uma posição de descomprometimento diante do cliente. L1 prossegue com o turno: "eu sei que tá anunciado no jornal... nê? Tá na promoção tudo...", o que caracteriza que o cliente já sabia da promoção. Notamos na construção do turno de L1 as formas verbais na voz passiva e no predicativo: "que tá anunciado"; "tá na promoção", o que origina a indeterminação sobre uma dissimulação que subtrai o comprometimento de L1 para com a informação e enfraquece também a falta de compromisso com a certeza do enunciado. Constatamos, ainda, que, ao tocar o celular, L1 interrompe a fala com o cliente e diz ao cliente, que está ausente da enunciação: "um minutinho", atendendo o celular em seguida. Esta forma de expressão, "minutinho", trata-se, também, de um minimizador cuja função é suavizar e aliviar a face negativa do cliente. Contudo, nesta situação temos a construção da cortesia negativa.

O uso do diminutivo em "um minutinho" suaviza o ato ameaçador da face negativa, visto que a fala é interrompida e o interlocutor precisa esperar o celular ser atendido. $\mathrm{Na}$ interação face a face, este fato se torna desagradável para o ouvinte, que precisa esperar o celular ser desligado para a retomada da fala.

Para Briz Gómez (2012). a indeterminação ou relativização acontece sobre um disfarce para subtrair a responsabilidade e compromisso do falante para com a informação ou o enunciado. Segundo Kerbrat-Orecchioni (2006, p.88), os minimizadores têm a "função de parecer reduzir o FTA", de algum modo que ele se apresente no enunciado, suavizando a ameaça que representa para as faces.

\section{Considerações finais}

Pelo estudo buscamos compreender que a cortesia verbal deve ser analisada contextualmente, haja vista que só se pode determinar se as ações ou atos são ou não corteses a partir de uma somatória de fatores que envolve a forma linguística, o contexto da enunciação e a relação subjetiva entre os interlocutores, as escolhas linguísticas, entre outros.

Neste sentido, a cortesia, do ponto de vista pragmático, não pode ser estudada de forma puramente gramatical, sendo necessário um estudo interlinguístico. A análise procurou mostrar a necessidade da presença dos procedimentos linguísticos da cortesia negativa para a atenuação dos atos de fala que ameaçam ambas as faces. Dessa forma, constatamos pelo contexto dos dois inquéritos que no primeiro: o uso do sujeito indeterminado contribuiu para atenuar a responsabilidade do falante da enunciação em relação ao conteúdo da proposição, servindo de escudo autoprotetor do falante, possibilitando resguardar a face negativa e, consequentemente, a construção do efeito da cortesia negativa. No segundo, o minimizador com o diminutivo em - inho 
contribui como um procedimento linguístico servindo para atenuar e enfraquecer a força argumentativa do falante com relação à verdade do enunciado proferido e com o compromisso da enunciação.

Se é que podemos estabelecer alguma diferença entre o minimizador e o sujeito indeterminado, essa consiste na função de parecer reduzir os atos que ameaçam as faces "FTA" para o minimizador. Na verdade, incide numa estratégia coercitiva porque, com o uso do diminutivo, o que se pretende é coagir o parceiro na comunicação, fazê-lo concordar com aquilo que desejamos. Por outro lado, o sujeito indeterminado apresenta o descomprometimento do falante com o conteúdo da informação, tornando a proposição generalizada. O modo como a cortesia é apresentada nesses inquéritos ocorreu por meio do apagamento da referência direta aos interlocutores e da coerção dos interlocutores com a aplicação do FTA, casos do minimizadores que parecem reduzir a ameaça do FTA.

Na pesquisa foi também possível identificar a língua falada de uma comunidade social e regional de Porto Velho em situações específicas, o que possibilitou observar o comportamento dos falantes da Região Norte do Brasil e descobrir a produção de um discurso híbrido, apresentando uma linguagem miscigenada, que advém das migrações de várias regiões do Brasil, que ainda persistem.

A cortesia, por se tratar de um processo dinâmico, define-se na interação com os alinhamentos e, sobretudo, quando se considera as reações do parceiro da comunicação. Somente dessa maneira pode-se avaliar porque Briz Gómez chama a cortesia de interpretada.

\section{REFERÊNCIAS}

ALBELDA, M. et al. Ficha metodológica para el análisis pragmático de la atenuación en corpus discursivos del español. (ES.POR.ATENUACIÓN). Oralia, Madri, n. 17, p. 7-62, 2014.

ALVAREZ MURO, A. (Des)Cortesía. Teoría y praxis de un sistema de significación. University of the Andes (Venezuela), 2014. Disponível em: www.researchgate.net/ publication/291147522. Acesso em: 14 maio 2018.

AUSTIN, J. L. Quando dizer é fazer. Tradução Danilo Marcondes de Souza Filho. Porto Alegre: Artes Médicas, 1990.

AUSTIN, J. L. How to do things with words. Cambridge, Harvard University Press, 1962. 
BRAVO, D. Imagem 'positiva' vs. imagem 'negativa'? Pragmatica socio-cultural y componentes de face. Oralia, v. 1, p. 155-184, 1999.

BRIZ GÓMEZ, E. A. A atenuação e os atenuadores: estratégias e táticas. Tradução Luiz Antônio da Silva, Adriana Marcelle de Andrade e Ramiro Carlos Humberto Caggiano Blanco. 2012 Disponível em: http://www.revistas.usp.br/linhadagua/article/view/64415/71564. Acesso em: 25 jul. 2018.

BROWN, P.; LEVINSON, S. C. Politeness: some universals in language usage. Cambridge: Cambridge University Press, 1987.

ESCANDELL-VIDAL, M. V. Cortesia, Fórmulas Convencionales y Estrategias Indiretas. Revista Española de Linguística (RSEL), n. 25, p. 25-31, 1995. Disponível em: http://www. uned.es/sel/pdf/ene-jun-95/25-1-Escandell.pdf. Acesso em: 09 ago. 2018.

FIORIN, J. L. A linguagem em uso. In: FIORIN, J. L. (org.). Introdução à Linguística. São Paulo: Contexto, 2012. p. 167-186.

FIORIN, J. L. Introdução à linguística. São Paulo: Contexto, 2002.

HAVERKATE, H. La Cortesía Verbal - Estudio pragmalinguístico. Madrid: Editorial Gredos, 1994.

HILGERT, J. G. A cortesia no monitoramento de problemas de compreensão da fala. In: GOFFMAN, E. Estigma: notas sobre a manipulação da identidade deteriorada. Tradução Márcia Bandeira de Mello Leite Nunes. Rio de Janeiro: LTC., 1975.

HILGERT, J. G. Polidez e preservação de face na fala de universitários. In: PRETI, D. (org.). Cortesia verbal. São Paulo: Humanistas, 2008.

GOFFMAN, E. Ritual de interação: ensaios sobre o comportamento face a face. Tradução Fabio R. R. Silva. Petrópolis: Editora Vozes, 2011.

GOFFMAN, E. A situação negligenciada. In: RIBEIRO, B. T.; GARCEZ, P. M. (org.). Sociolingüística interacional. 2. ed. São Paulo: Loyola, 2002.

GOFFMAN, E. A representação do eu na vida cotidiana. Petrópolis: Vozes, 1975. 
GOFFMAN, E. Interaction ritual. Essays on face-to-face behavior. New York: Anchor Books, 1967.

GRICE, H. P. Logic and Conversation. In: COLE, P.; MORGAN, J (ed.). Syntax and Semantics. v. 3: Speechs Acts. New York: Academic Press, 1968. p. 41-58. [Tradução para a língua portuguesa de João Wanderley Geraldi. Lógica e Conversação. In: DASCAL, M. (org.). Fundamentos Metodológicos da Linguística - v. IV. Campinas: Editora do Autor, 1982. p. 81-104.]

GRICE, H. P. The logic and conversation. University of California, Berkeley, 1975.

KERBRAT-ORECCHIONI, C. Análise da conversação: princípios e métodos. São Paulo: Parábola, 2006.

KERBRAT-ORECCHIONI, C. Os atos de linguagem no discurso: teoria e funcionamento. Niterói: EdUFF, 2006.

KERBRAT-ORECCHIONI, C. Les interactions verbales. Paris: Armand Colin, 1992. Tomo II.

LAKOFF, R. The language of politeness. Papers from the Ninth Regional Meeting of the Chicago Linguistic Society, p. 293-305, 1973.

LAKOFF, R. The Logic of Politeness; or, Minding your P's and Q's. Papers from the Ninth Regional Meeting of the Chicago Linguistic Society, p. 292-305, 1973.

PRETI, D. (org.). Cortesia verbal. São Paulo: Humanitas, 2008.

SEARLE, J. Speech acts. Tradução Carlos Vogt et ali. Coimbra: Livraria Almedina, 1981.

SEARLE, J. Speech acts. Cambridge: Cambridge University Press, 1969.

SILVA, L. A. da. Cortesia e formas de tratamento. In: PRETI, D. (org.). Cortesia verbal. São Paulo: Humanitas, 2008. p. 157-192. 